\title{
Meningeal carcinomatosis underdiagnosis and overestimation: incidence in a large consecutive and unselected population of breast cancer patients
}

Gloria Mittica', Rebecca Senetta ${ }^{2}$, Lorenzo Richiardi ${ }^{2}$, Roberta Rudà ${ }^{3}$, Renato Coda ${ }^{2}$, Isabella Castellano ${ }^{2 *}$, Anna Sapino ${ }^{2}$ and Paola Cassoni ${ }^{2}$

\begin{abstract}
Background: The incidence of meningeal carcinomatosis appears to be higher than in the past due to advances in neuro-imaging diagnostic techniques and improvements in cancer survival. Among solid tumors, breast cancer is the cancer most commonly associated with meningeal carcinomatosis, with an incidence rate of between 0.8 and $16 \%$. Aim of this study has been i) to evaluate the incidence of meningeal carcinomatosis in a continuous breast cancer unselected series treated in a dedicated Breast Unit and ii) to define the clinico-pathological and molecular parameters associated with meningeal carcinomatosis development.

Methods: A retrospective series of 1915 consecutive patients surgically treated for breast cancer between 1998 and 2010 was collected. Clinico-pathological data were recorded from medical charts and pathological reports, including the date of development of symptomatic meningeal carcinomatosis. Meningeal carcinomatosis incidence was determined at both 5- and 10-year follow-ups.

Results: Three patients in the first 5 years of follow-up and six patients in 10 years of follow-up developed meningeal carcinomatosis. An incidence rate of 5.44 per 10,000 patients (95 \% Cl: 1.75-16.9) was observed, with a 5-year risk of $0.3 \%$. At 10-year follow up, the rate increased to 7.55 per 10,000 patients (95 \% Cl: 3.39-16.8). In a univariate analysis, young age, tumor size larger than $15 \mathrm{~mm}$, histological grade 3, more than three metastatic lymph nodes, negative estrogen receptor, positive HER2 and high proliferative index were significantly associated with meningeal carcinomatosis development.

Conclusions: In an unselected breast cancer population, meningeal carcinomatosis is a rare event that is associated with adverse prognostic factors. Meningeal carcinomatosis incidence is overestimated when recorded in biased/high-risk selected breast cancer patients and should not be considered to accurately reflect the overall breast cancer population.
\end{abstract}

Keywords: Meningeal carcinomatosis, Breast cancer, Incidence

\footnotetext{
* Correspondence: isabella.castellano@unito.it

${ }^{2}$ Department of Medical Sciences, University of Turin, Via Santena 7, 10126

Turin, Italy

Full list of author information is available at the end of the article
} 


\section{Background}

Meningeal carcinomatosis (MC) is caused by the spread of cancer cells to the leptomeninges and by their dissemination within the cerebrospinal fluid (CSF). MC has been reported to occur in 5-10 \% of all solid tumors, mainly in breast cancer (BC), lung cancer and malignant melanoma in adult patients $[1,2]$. In particular, $\mathrm{MC}$ represents a well-known complication in $\mathrm{BC}$ [3-5]; in recent years, its occurrence has increased in this patient setting, mainly due to advances in neuro-imaging techniques and to remarkable improvements in BC survival. However, to date, few studies have described the true incidence of $\mathrm{MC}$ in $\mathrm{BC}$ patients, and the results have proved controversial. In fact, the reported estimates of $\mathrm{MC}$ occurrence vary considerably, ranging from 0.8 to $6.6 \%$ in clinical reports to $2.6-16 \%$ in autopsy series [6-14]. Patients with MC clinically present with subtle and heterogeneous signs and symptoms that depend on the anatomical site involved (cerebral hemispheres, cranial nerves, and/or spinal cord) [5, 15-17]. Diagnosis is based on cytological CSF examination and/or magnetic resonance imaging (MRI); these tests reportedly exhibit a sensitivity ranging from 45 to $80 \%$ for CSF examination and from 20 to $91 \%$ for MRI $[5,18]$. Currently, therapeutic strategies include radiotherapy and intrathecal or systemic chemotherapy; however, the results remain poor because late diagnosis usually leads to non-eligibility of patients for treatment and to the delivery of palliative care only [19]. An earlier MC diagnosis could also improve the quality of life of $\mathrm{BC}$ patients who sometimes rapidly progress and need of institutional/hospital care. In fact, survival ranges from 4 to 6 weeks from diagnosis in untreated patients to 6 months when patients are immediately subjected to aggressive treatment [20, 21]. Longer survival is reported in only a few cases $(13 \%$ at 1 year and $6 \%$ at 2 years) [16].

Few data are available that focus on the association of $\mathrm{MC}$ with peculiar clinico-morphological-molecular features in BC patients, and no studies has effectively pinpointed specific predictors of $\mathrm{MC}$ development. The most common parameters that have been identified to date are: young age, $\geq 4$ metastatic lymph nodes, high histological tumor grade, HER2-positive status and triple negative immune-phenotype [10, 22-26]. Recently, a significant association with lobular histological type, estrogen receptor (ER) and progesterone receptor (PR)negative status have been highlighted, as well as the presence of metastases at diagnosis [27].

In this context, the aim of this study is twofold: (1) to estimate the incidence of $\mathrm{MC}$ in a large cohort of consecutive and unselected $\mathrm{BC}$ patients who were treated in the same Breast Unit and (2) to define which clinico-pathological and molecular parameters, if any, are significantly associated with MC development in order to identify patients at high risk at an earlier stage.

\section{Methods \\ Cohort definition and follow-up procedures}

Our initial cohort included a consecutive series of BC cases comprising the entire population of 2017 patients who underwent surgery at the Città della Salute e della Scienza of Turin between 1998 and 2010.

For all patients, follow-up data were retrieved from the oncologists' clinical records, and the last visit recorded in the cohort was registered on November 21st, 2013.

The study was submitted to and approved by the Ethic Institutional Review Board for "Biobanking and use of human tissues for experimental studies" of the Pathology Service of the Azienda Ospedaliera Città della Salute e della Scienza di Torino, Torino, Italy. The project provided a verbal and not written informed consent from the patients due to the retrospective approach of the study, which did not impact on their treatment. All the cases were anonymously recorded. The Institutional Review Board approved this consent procedure.

To accurately estimate the MC incidence rate, the starting date for the analyses was set at January 1st, 2005, when MC started to be systematically recorded in the Department of Neuro-Oncology of our Hospital in $\mathrm{BC}$ population. Therefore, even though the follow up started at the time of surgery, just in the subgroup of patients who underwent surgery before the first of January 2005 , this date was considered as the initial period of observation. The follow up ended at the last visit or at MC diagnosis. Consequently, from the initial cohort of 2017 patients, we excluded 50 patients without any follow up data (lost) and 52 patients whose follow up ended before the first of January 2005 (because MC was never investigated in this subgroup of patients). Therefore, 1915 patients were considered in further analyses (Fig. 1).

To enhance the study validity, we restricted the main analysis to the first 5 years of follow up after surgery, because most of the patients regularly participated in the scheduled visits during this initial period, with very limited loss during follow up. For this analysis, which was limited to the first 5 years of follow up, we excluded 122 additional patients who underwent surgery more than 5 years before the 1st of January, 2005, even though they were still in follow up at this time. Therefore, the final analysis, in which $\mathrm{MC}$ incidence rate was estimated during the first 5 years of follow up, included 1793 patients (Fig. 1).

As an additional study group, we considered the entire population of 1915 patients in an extended 10-year 


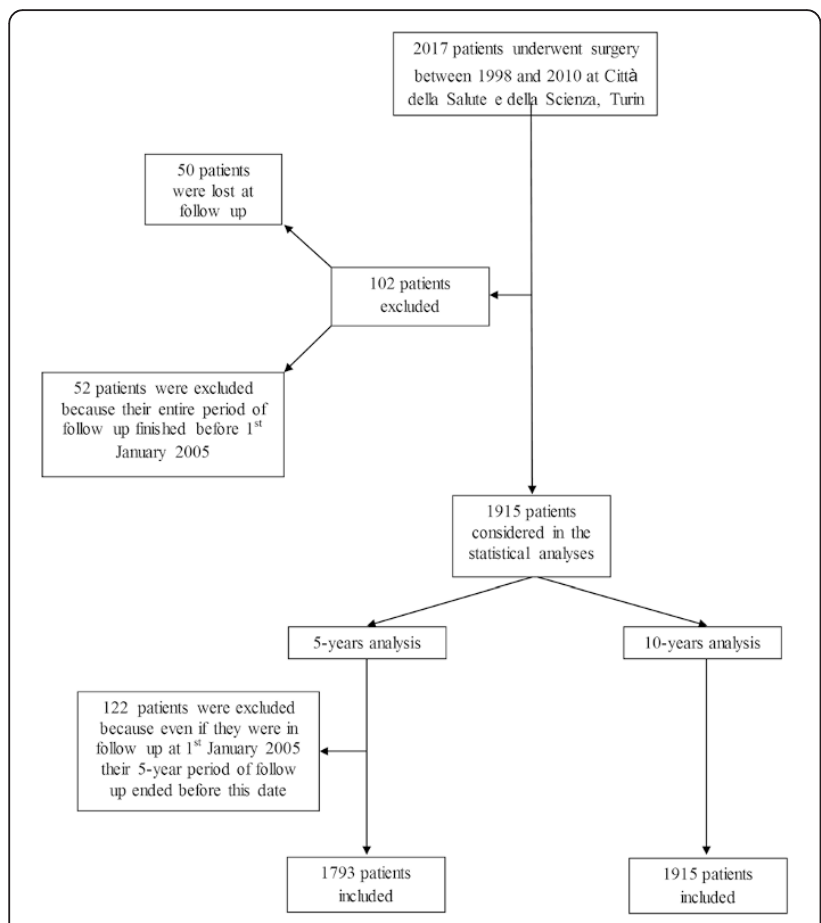

Fig. 1 Patient series included in the study

follow up (Fig. 1); in this analysis, MC incidence estimates are based on a larger number of events but are potentially biased due to lower compliance at the scheduled follow-up visits from 5 to 10 years after surgery. Further extension of the follow-up up to 15 years would introduce even greater bias, as all patients with no complications are referred to their general practitioner 10 years after BC diagnosis. Only patients with complications or disease recurrence (including $\mathrm{MC}$ ) are still followed by the Breast Unit at the hospital.

\section{Clinical and pathological features}

For each case, clinical, morphological, immunohistochemical and molecular data were collected. MC was suspected in patients upon initial neurological symptoms that are suggestive of meningeal involvement (i.e., headache, cranial nerve palsy, back pain, radicular pain, leg weakness, etc.). Clinical diagnoses were confirmed based on positive abnormal brain or spinal cord MRI and/or positive CSF cytology.

\section{Statistical analysis}

All statistical analyses were conducted using the software STATA 11. We first estimated the incidence rate of $\mathrm{MC}$, including $95 \%$ confidence intervals $(\mathrm{CI})$, over the first 5 years or the first 10 years of follow up after surgery for $\mathrm{BC}$. The cumulative risks of $\mathrm{MC}$ over 5-year and 10-year after diagnosis of $\mathrm{BC}$ were estimated using Kaplan-Meier analysis.
In addition, despite the limited number of $\mathrm{MC}$ cases, the clinical, morphological and molecular characteristics of the case series were studied to determine whether any feature of the primary tumor was predictive of higher $\mathrm{MC}$ risk. Several a priori selected variables, including age, type of surgery, grading, lymph node involvement, tumor size, vascular invasion, ER and PR status, Ki-67 immunostaining and HER2 expression, were considered. Variables were categorized according to the literature and international guidelines [28-32]. Due to the very limited number of events, only univariate analyses were conducted.

\section{Results}

The 1915 BC patients were women aged 22-93 (mean age 61.2 years) and included 338 patients (17.6\%) younger than 50 years. Clinical and morphological data regarding these women are reported in Table 1, column A.

Overall, we identified nine cases of MC out of 1915 $\mathrm{BC}$ patients. Three out of nine patients developed leptomeningeal involvement more than 10 years after their primary $\mathrm{BC}$ surgery and were therefore excluded from the analyses. The clinico-pathological features of the 6 patients with $\mathrm{MC}$ included in this study are summarized in Table 1, column B.

\section{Incidence and risk of MC}

The median follow up period for the 1793 patients included in the analyses that were limited to the first 5 years of follow up was 4.78 years, and $47 \%$ of the patients were followed up for the full 5 years. When analyses were prolonged until 10 years of follow up (1915 patients), the median follow up period was slightly increased to 5.03 years, and only $7 \%$ of the patients were followed up for the full 10-year period.

In the first 5 years of follow up, three patients developed MC, corresponding to a rate of 5.44 per 10,000 patients per year (95\% CI: 1.75-16.9) and an overall 5year risk of $0.3 \%$ (95\% CI: 0.1-0.8) (Table 2, column A). Extending the period of observation to 10 years of follow up revealed a rate of 7.55 per 10,000 patients per year (0.6 \% 10-year risk, $95 \%$ CI: $0.3-1.4)$, based on six MC patients.

\section{Clinico-pathological features and MC development}

Among the 6 patients who developed MC, the median age at time of $\mathrm{BC}$ diagnosis was 39.5 years (range, 32 to 49 years) and all patients showed a tumor size larger than $15 \mathrm{~mm}$. The most common histological subtype was infiltrative ductal carcinoma (5/6 cases) with a high $(66.7 \%)$ or intermediate (33.3\%) histological tumor grade. Three of the six patients $(50 \%)$ had more than three axillary lymph node metastases. ER and PR immunostain was positive in $50 \%$ of cases; in $66.7 \%$ of BC 
Table 1 Clinico-pathological and molecular features of 1915 patients who were included in our analyses and underwent surgery between 1998 and 2010 (column A), highlighting the features of 6 patients with MC occurring during the first 10 years of follow up and considered in the analyses (column B)

\begin{tabular}{lll}
\hline Collected parameters & Column A & Column B \\
& Patients & Patients with \\
& $n=1915(\%)$ & MC $n=6(\%)$
\end{tabular}

Age at diagnosis of $B C$

$-<50$ years

$-\geq 50$ years

$338(17.6 \%) \quad 6(100 \%)$

$1577(82.4 \%) \quad 0$

Treatment

- T (umorectomy)

- M (astectomy)

Histological type

- IDC

$-\mid \mathrm{ILI}$

- Mixed IDC-ILI

- Others

Histological grade

$-\mathrm{G} 1$

$-G 2$

- G3

- Not available

Tumor size

- $\leq 15 \mathrm{~mm}$

- > $15 \mathrm{~mm}$

- Not available

Vascular invasion

- No

- Yes

- Not available

pT stage

- pT1

- pT2

- pT3-4

- Not available

pN stage

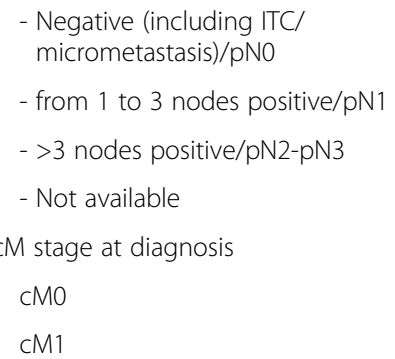

Bone metastases

$1335(69.7 \%) \quad 1$ (16.7\%)

$\begin{array}{ll}338(17.7 \%) & 2(33.3 \%) \\ 167(8.7 \%) & 3(50 \%) \\ 75(3.9 \%) & 0\end{array}$

$1889(98.6 \%) \quad 4(66.7 \%)$

$26(1.4 \%) \quad 2(33.3 \%)$

$1818(94.9 \%) \quad 3(50 \%)$
Table 1 Clinico-pathological and molecular features of 1915 patients who were included in our analyses and underwent surgery between 1998 and 2010 (column A), highlighting the features of 6 patients with MC occurring during the first 10 years of follow up and considered in the analyses (column B)

(Continued)

\begin{tabular}{|c|c|c|}
\hline - yes & $97(5.1 \%)$ & $3(50 \%)$ \\
\hline \multicolumn{3}{|l|}{ Brain metastases } \\
\hline- no & 1898 (99.1%) & $1(16.7 \%)$ \\
\hline - yes & $17(0.9 \%)$ & $5(83.3 \%)$ \\
\hline \multicolumn{3}{|c|}{ Metastases in other site, NAS } \\
\hline- no & $1686(88 \%)$ & 0 \\
\hline - yes & $229(12 \%)$ & $6(100 \%)$ \\
\hline \multicolumn{3}{|l|}{ ER status } \\
\hline Negative & $190(9.9 \%)$ & $3(50 \%)$ \\
\hline Positive & $1693(88.4 \%)$ & $3(50 \%)$ \\
\hline Not available & $32(1.7 \%)$ & 0 \\
\hline \multicolumn{3}{|l|}{ PR status } \\
\hline - Negative & $256(13.4 \%)$ & $2(33.3 \%)$ \\
\hline - Positive & $1365(71.3 \%)$ & $3(50 \%)$ \\
\hline - Not available & 294 (15.4 \%) & $1(16.7 \%)$ \\
\hline \multicolumn{3}{|l|}{ Ki67 } \\
\hline$-<20 \%$ & $1103(57.6 \%)$ & $2(33.3 \%)$ \\
\hline$-\geq 20 \%$ & 741 (38.7 \%) & $4(66.7 \%)$ \\
\hline - Not available & $71(3.7 \%)$ & 0 \\
\hline \multicolumn{3}{|l|}{ HER2 } \\
\hline - negative & $1662(86.8 \%)$ & $3(50 \%)$ \\
\hline - positive & $151(7.9 \%)$ & $3(50 \%)$ \\
\hline - Not available & $101(5.3 \%)$ & 0 \\
\hline \multicolumn{3}{|c|}{ Neoadjuvant chemotherapy } \\
\hline$-\mathrm{No}$ & 1836 (95.9 \%) & $3(50 \%)$ \\
\hline - Yes & $79(4.1 \%)$ & $3(50 \%)$ \\
\hline \multicolumn{3}{|l|}{ Adjuvant treatment } \\
\hline - Chemotherapy & $722(37.7 \%)$ & $4(66.7 \%)$ \\
\hline - Radiotherapy & 1352 (70.6 \%) & $1(16.7 \%)$ \\
\hline - Hormone therapy & $1520(79.4 \%)$ & $2(33.3 \%)$ \\
\hline
\end{tabular}

IDC Infiltrating ductal carcinoma, ILC Infiltrating lobular carcinoma, $G$ histological tumor grade [28], ITC isolated tumor cells cases, Ki67 was higher than $20 \%$. HER2 status was positive in $3 / 6$ cases $(50 \%)$. Vascular invasion was present in five cases $(83.3 \%)$.

Univariate analysis showed that younger age, tumor size more than $15 \mathrm{~mm}$, high histological tumor grade (G3), ER-negative status, HER2-positive status and high proliferative index were associated with MC development, considering the first 5 years of follow up (Table 2, column A). These associations were replicated in the analyses based on 10 years of follow-up extended 
Table 2 Rate of breast cancer-related meningeal carcinomatosis, 5 years (column A) and 10 years (column B) after surgery

\begin{tabular}{|c|c|c|c|c|c|c|c|c|}
\hline & \multicolumn{4}{|c|}{ Column A: 5-year follow up ${ }^{a}$} & \multicolumn{4}{|c|}{ Column B: 10-year follow up } \\
\hline & MC events & Patients & Person-years & Rate (per 10.000) & MC events & Patients & Person-years & Rate (per 10.000) \\
\hline Patients & 3 & 1793 & 5518 & $5.44(1.75-16.9)$ & 6 & 1915 & 7947 & $7.55(3.39-16.8)$ \\
\hline \multicolumn{9}{|l|}{ Age at diagnosis } \\
\hline$-<50$ years & 3 & 324 & 999 & $30.0(9.69-93.1)$ & 6 & 338 & 1446 & $41.1(18.6-92.4)$ \\
\hline \multirow[t]{2}{*}{ - $\geq 50$ years } & 0 & 1469 & 4519 & 0 & 0 & 1577 & 6502 & 0 \\
\hline & & & & $(p=0.002)$ & & & & $(p<0.001)$ \\
\hline \multicolumn{9}{|l|}{ Treatment } \\
\hline -Tumorectomy & 2 & 1325 & 4146 & $4.82(1.21-19.3)$ & 2 & 515 & 1972 & $20.3(7.61-54.0)$ \\
\hline \multirow[t]{2}{*}{-Mastectomy } & 1 & 468 & 1372 & $7.29(1.03-51.7)$ & 4 & 1400 & 5975 & $3.34(0.84-13.4)$ \\
\hline & & & & $(p=0.73)$ & & & & $(p=0.018)$ \\
\hline \multicolumn{9}{|l|}{ Histological grade } \\
\hline$-\mathrm{G} 1$ & 0 & 528 & 1515 & 0 & 0 & 564 & 2323 & 0 \\
\hline$-G 2$ & 0 & 854 & 2770 & 0 & 2 & 908 & 3799 & $5.26(1.32-21.0)$ \\
\hline \multirow[t]{2}{*}{$-\mathrm{G} 3$} & 3 & 403 & 1211 & 24.8 (7.99-76.8) & 4 & 435 & 1794 & $22.3(8.4-59.4)$ \\
\hline & & & & $(p<0.001)$ & & & & $(p=0.007)$ \\
\hline \multicolumn{9}{|l|}{ Tumor size } \\
\hline$-\leq 15 \mathrm{~mm}$ & 0 & 949 & 2927 & 0 & 0 & 1019 & 4280 & 0 \\
\hline \multirow[t]{2}{*}{$->15 \mathrm{~mm}$} & 3 & 838 & 2581 & $11.6(3.75-36.0)$ & 6 & 890 & 3649 & 16.4 (7.39-36.6) \\
\hline & & & & $(p=0.07)$ & & & & $(p=0.008)$ \\
\hline \multicolumn{9}{|l|}{ Vascular invasion } \\
\hline - No & 1 & 1204 & 3779 & $2.64(0.37-18.8)$ & 1 & 1271 & 5323 & $1.88(0.26-13.3)$ \\
\hline \multirow[t]{2}{*}{ - Yes } & 2 & 574 & 1697 & $11.8(2.95-47.1)$ & 5 & 626 & 2558 & $19.5(8.13-47.0)$ \\
\hline & & & & $(p=0.18)$ & & & & $(p=0.008)$ \\
\hline \multicolumn{9}{|l|}{ pT stage } \\
\hline - pT1 & 1 & 1262 & 3945 & $2.53(0.36-18.0)$ & 1 & 1342 & 5683 & $1.76(0.25-12.5)$ \\
\hline - pT2 & 2 & 461 & 1394 & $14.3(3.59-57.4)$ & 5 & 493 & 1984 & $25.2(10.5-60.5)$ \\
\hline \multirow[t]{2}{*}{ - pT3-4 } & 0 & 66 & 172 & 0 & 0 & 76 & 269 & 0 \\
\hline & & & & $(p=0.30)$ & & & & $(p=0.01)$ \\
\hline \multicolumn{9}{|l|}{ pN stage } \\
\hline $\begin{array}{l}\text { - Negative (including ITC/ } \\
\text { micrometastasis)/pNO }\end{array}$ & 1 & 1273 & 3981 & $2.51(0.35-17.8)$ & 1 & 1335 & 5594 & $1.79(0.25-12.7)$ \\
\hline - from 1 to 3 positive/pN1 & 1 & 319 & 1006 & $9.94(1.40-70.6)$ & 2 & 338 & 1452 & $13.8(3.44-55.1)$ \\
\hline \multirow[t]{2}{*}{ - >3 positives/pN2-pN3 } & 1 & 149 & 391 & $25.6(3.61-182)$ & 3 & 167 & 604 & $49.7(16.0-154)$ \\
\hline & & & & $(p=0.26)$ & & & & $(p=0.004)$ \\
\hline \multicolumn{9}{|l|}{ ER status } \\
\hline - Negative & 2 & 181 & 532 & $37.6(9.40-150)$ & 3 & 190 & 776 & $38.6(12.5-119)$ \\
\hline \multirow[t]{2}{*}{ - Positive } & 1 & 1581 & 4869 & $2.05(0.89-14.6)$ & 3 & 1693 & 7015 & $4.28(1.38-13.3)$ \\
\hline & & & & $(p=0.001)$ & & & & $(p=0.001)$ \\
\hline \multicolumn{9}{|l|}{ PR status } \\
\hline - Negative & 2 & 231 & 653 & $15.3(2.16-109)$ & 2 & 256 & 966 & $10.4(1.46-73.5)$ \\
\hline \multirow[t]{2}{*}{ - Positive } & 1 & 1270 & 4090 & $4.89(1.22-19.6)$ & 3 & 1365 & 5496 & $7.28(2.73-19.4)$ \\
\hline & & & & $(p=0.054)$ & & & & $(p=0.19)$ \\
\hline \multicolumn{9}{|l|}{ Ki67 } \\
\hline$-<20 \%$ & 0 & 1041 & 3224 & 0 & 2 & 1103 & 4600 & $4.35(1.09-17.4)$ \\
\hline
\end{tabular}


Table 2 Rate of breast cancer-related meningeal carcinomatosis, 5 years (column A) and 10 years (column B) after surgery (Continued)

\begin{tabular}{lllllllll}
\hline$-\geq 20 \%$ & 3 & 685 & 2037 & $\begin{array}{l}14.7(4.75-45.7) \\
(\boldsymbol{p}=\mathbf{0 . 0 3})\end{array}$ & 4 & 741 & $\begin{array}{c}2990 \\
13.4(5.02-35.6) \\
(p=0.17)\end{array}$ \\
HER2 & & & & & & & \\
- Negative & 1 & 1574 & 4875 & $2.05(0.29-14.6)$ & 3 & 1662 & 6867 & $4.37(1.41-13.5)$ \\
- Positive & 2 & 144 & 452 & $44.2(11.01-177)$ & 3 & 151 & $632 \quad$ & $47.5(15.3-147)$ \\
& & & & $(\boldsymbol{p}<\mathbf{0 . 0 0 1 )}$ & & & $(\boldsymbol{p}<\mathbf{0 . 0 0 1 )}$ \\
\hline
\end{tabular}

ITC isolated tumor cells

amissing data: Grading: 8 missing; pN stage: 52 missing; tumor size: 6 missing; ER: 31 missing; PR: 292 missing; Ki67: 67 missing; Vascular invasion: 15 missing; pT stage: 4 missing; HER2: 75 missing

${ }^{b}$ missing data: Grading: 8 missing; pN stage: 75 missing; tumor size: 6 missing; ER: 32 missing; PR: 294 missing; Ki67: 71 missing; Vascular invasion: 18 missing; pT stage: 4 missing; HER2: 101 missing

analysis; in the latter analyses, the higher $\mathrm{pT}$, more than three metastatic lymph nodes and presence of vascular invasion were also associated with an increased risk of MC (Table 2, column B).

Finally, it appears that the rate of $\mathrm{MC}$ was higher in the subgroup of patients with bone and/or brain metastases (Table 3).

\section{Discussion}

MC diagnosis has increased in recent years due to advances in imaging technology and the development of new chemotherapy and immunotherapy approaches that have improved the survival of patients with BC. Despite the observed increase in clinical practice [27, 33], our results suggest that the incidence of MC remains low, when considering an unselected population undergoing surgery for $\mathrm{BC}$. To date, few studies have analyzed the occurrence of $\mathrm{MC}$ in patients with $\mathrm{BC}$, and the results vary depending on the study approach used. Briefly, in advanced stages and autopsy series, MC incidence was observed with rates ranging from 2.6 to $16 \%$ [9, 11-14]. In a retrospective study based on a selected subgroup of $\mathrm{BC}$ patients with metastatic disease, Yap et al. reported a $5 \%$ incidence [6]. More recently, in a series of $\mathrm{BC}$ with
HER2 overexpression, MC incidence was observed in up to $6.6 \%$ of cases [8]. However, these relevant percentages need to be critically interpreted because they have been observed in selected high-risk categories of patients with $\mathrm{BC}$. The question then arises, what is the incidence of $\mathrm{MC}$ in an unselected population with $\mathrm{BC}$ ? To address this issue, we decided to apply a rigorous definition of our BC cohort to avoid selection bias. In fact, we included all patients with $\mathrm{BC}$ who were consecutively treated in our Breast Unit, not only those with metastatic/advanced disease or with high-risk parameters. In addition, we first restricted the main analyses to patients who were expected to attend with high compliance during the periodic follow up; that is, the large subgroup of patients who regularly attended scheduled visits (approximately every 6 months) in the first 5 years after BC diagnosis and surgery, regardless to disease stage.

In this well-defined cohort, 3 patients developed MC, with a rate of incidence of 5.44 per 10,000 per year and a 5 -year risk of $0.3 \%$. Because some studies have reported that the incidence of $\mathrm{MC}$ is most common in patients with $\mathrm{BC}$ after 10 years from diagnosis [15, 34], we also conducted an additional 10-year follow up analysis. During this period, we registered 3 additional cases

Table 3 Rate of breast cancer related to meningeal carcinomatosis in patients with bone and/or brain metastasis occurrence: 5 years (column A) and 10 years (column B) after surgery

\begin{tabular}{|c|c|c|c|c|c|c|c|c|}
\hline & \multicolumn{4}{|c|}{ Column A: 5-year follow up } & \multicolumn{4}{|c|}{ Column B: 10-year follow up } \\
\hline & MC events & Patients & Person-years & Rate (per 100) & MC events & Patients & Person-years & Rate (per 100) \\
\hline \multicolumn{9}{|c|}{ Occurrence of bone metastasis ${ }^{a}$} \\
\hline No & 2 & 1780 & 5434 & $0.037(0.0092-0.147)$ & 3 & 1898 & 7770 & $0.039(0.012-0.12)$ \\
\hline \multirow[t]{2}{*}{ Yes } & 1 & 52 & 84 & $1.19(0.168-0.85)$ & 3 & 87 & 177 & $1.69(0.55-5.25)$ \\
\hline & & & & $(p<0.001)$ & & & & $(p<0.001)$ \\
\hline \multicolumn{9}{|c|}{ Occurrence of brain metastasis } \\
\hline No & 2 & 1792 & 5510 & $0.036(0.0091-0.15)$ & 3 & 1912 & 7929 & $0.038(0.012-0.12)$ \\
\hline \multirow[t]{2}{*}{ yes } & 1 & 9 & 7 & $14.36(2.02-101.93)$ & 3 & 15 & 18 & $16.58(5.35-51.41)$ \\
\hline & & & & $(p<0.001)$ & & & & $(p<0.001)$ \\
\hline
\end{tabular}

aatients sum up to more than 1793 (5-year follow-up) or 1915 (10-year follow-up) because bone and brain metastases are time-dependent variables; thus, a single patient who developed metastasis during the follow up contributed to both levels (yes and no) of the variable 
of $\mathrm{MC}$, which determined a non-substantial increase in the rate of $\mathrm{MC}$ incidence. Overall, in our consecutive and unselected population of patients with $\mathrm{BC}$ who were treated and followed in the same Breast Unit, the 5- and 10-year risk rates of $\mathrm{MC}$ development were lower than $1 \%$. Similarly, brain metastases occurred in $0.9 \%$ of the cohort (and $83 \%$ of MC exhibited an associated brain lesion). These results appear similar to those reported two decades ago by Jayson et al., who described a $0.86 \%$ incidence rate of $\mathrm{MC}$ in an unselected series of patients with $\mathrm{BC}$ [7]. In the same study, focusing on a subgroup of patients treated for recurrent disease, an increased incidence of up to approximately $2 \%$ was observed [7].

To our knowledge, this was the only study to examine the unbiased incidence rate of $\mathrm{MC}$ in $\mathrm{BC}$, and the consistency of the results with our data obtained 20 years later leads to two hypotheses: either the "real" incidence of $\mathrm{MC}$ in an unselected $\mathrm{BC}$ population has undergone an apparent, but not true increase, or the "real" incidence remains underestimated.

Considering that patients with $\mathrm{BC}$ and neurological symptoms may be referred to the emergency room or to a neurological setting (where $\mathrm{MC}$ is usually managed), we can hypothesize that the source of the data (Breast Unit medical charts) might represent a limitation.

As a second step, we attempted to solve the important and partially unmet need to identify patients with $\mathrm{BC}$ who are at high risk for MC development; to this end, we searched for clinico-pathological and molecular features that might be useful as possible predictors of increased MC risk. We observed that established predictors of worse prognosis (young age, tumor size exceeding $15 \mathrm{~mm}$, high histological grade, more than three metastatic lymph nodes, ER-negative and HER2-positive status and high proliferative index) were associated with an increased risk of $\mathrm{MC}$, in agreement with other studies [25, 27, 35-39].

\section{Conclusions}

$\mathrm{MC}$ remains a rare condition with a usual occurrence in the natural history of $\mathrm{BC}$. Late diagnosis of $\mathrm{MC}$ leads patients to non-eligibility for standard therapeutic strategies, including radiotherapy and intrathecal and/or systemic chemotherapy and to the delivery of palliative care. Consequently, the identification of a clinicopathological profile of patients with $\mathrm{BC}$ who are at increased MC risk would be useful so that they might be directed to a strict follow up aimed at anticipating $\mathrm{MC}$ diagnosis prior to symptom presentation, as also suggested by a recent review of clinical trials [40]. However, the low incidence of $\mathrm{MC}$ and the lack of specific risk factors make it difficult to generate a dedicated diagnostic screening work up that is designed to precociously detect $\mathrm{MC}$ in patients with $\mathrm{BC}$.

\section{Abbreviations}

BC: Breast Cancer; CSF: Cerebrospinal fluid; ER: Estrogen Receptor; MC: Meningeal Carcinomatosis; MRI: Magnetic Resonance Imaging; PR: Progesterone Receptor.

\section{Competing interests}

The authors declare that they have no competing interests.

\section{Authors' contributions}

Study concepts: PC and AS. Study design: IC and RS. Data acquisition: GM and RR. Quality control of data and statistical analysis: LR. Data analysis and interpretation: PC. Manuscript preparation: GM and RS. Manuscript editing: IC and RC. All authors read and approved the final manuscript. All the contributors meet the ICMJE guidelines for authorship.

\section{Acknowledgements}

This paper was supported by grants from FIRC (Fondazione Italiana per la Ricerca sul Cancro) and Progetti di Ricerca finanziati dall'Università degli Studi di Torino (ex 60 \% 2013 and 2014 to PC).

\section{Author details}

${ }^{1}$ Division of Medical Oncology, University of Turin Medical School, Fondazione del Piemonte per l'Oncologia-Institute for Cancer Research and Treatment of Candiolo, Strada Provinciale 142 km 3,95, 10060 Candiolo, Turin, Italy. ${ }^{2}$ Department of Medical Sciences, University of Turin, Via Santena 7, 10126 Turin, Italy. ${ }^{3}$ Department of Neuro-Oncology, University and City of Health and Science Hospital, Via Cherasco 15, 10126 Turin, Italy.

Received: 14 May 2015 Accepted: 21 December 2015

Published online: 29 December 2015

References

1. Van Horn A, Chamberlain MC. Neoplastic meningitis. J Support Oncol. 2012; 10:45-53.

2. Meriggi F, Zaniboni A. Newer avenues for the treatment of leptomeningeal carcinomatosis. Cent Nerv Syst Agents Med Chem. 2011;11:38-44.

3. Kesari S, Batchelor T. Leptomeningeal metastases. Neurol Clin N Am. 2003; 21:25-66.

4. Clarke JL, Perez HR, Jacks LM, Panageas KS, Deangelis LM. Leptomeningeal metastases in the MRI era. Neurology. 2010;74:1449-54.

5. Le Rhun E, Taillibert S, Chamberlain MC. Carcinomatous meningitis: leptomeningeal metastases in solid tumors. Surg Neurol Int. 2013;4 Suppl 4: 265-88.

6. Yap HY, Yap BS, Tahima CK, DiStefano A, Blumenschein GR. Meningeal carcinomatosis in breast cancer. Cancer. 1978:42:283-6.

7. Jayson GC, Howell A, Harris M, Morgenstern G, Chang J, Ryder WD. Carcinomatous meningitis in breast cancer: an aggressive disease variant. Cancer. 1994;74:3135-41.

8. Boogerd W, Hart AA, van der Sande JJ, Engelsman E. Meningeal carcinomatosis in breast cancer: prognostic factors and influence of treatment. Cancer. 1991;67:1685-95.

9. Smith DB, Howell A, Harris M, Bramwell VH, Sellwood RA. Carcinomatous meningitis associated with infiltrating lobular carcinoma of the breast. Eur J Surg Oncol. 1985;11:33-6.

10. Bendell JC, Domchek SM, Burnstein HJ, Harris L, Younger J, Kuter I, et al. Central nervous system metastases in women who receive trastuzumabbased therapy for metastatic breast carcinoma. Cancer. 2003;97:2972-7.

11. Lamovec J, Zidar A. Association of leptomeningeal carcinomatosis in carcinoma of the breast with infiltrating lobular carcinoma. An autopsy study. Arch Pathol Lab Med. 1991;115:507-10.

12. Tsukada Y, Fouad A, Pickren JW, Lane WW. Central nervous system metastasis from breast carcinoma. Autopsy Study Cancer. 1983:52:2349-54.

13. Lee YT. Breast carcinoma: pattern of metastasis at autopsy. J Surg Oncol. 1983;23:175-80.

14. Lin NU, Bello JR, Winer EP. CNS metastases in breast cancer. J Clin Oncol. 2004;22:3608-17.

15. Balm M, Hammack J. Leptomeningeal carcinomatosis: presenting features and prognostic factors. Arch Neuro. 1996;53:626-32.

16. Jaeckle KA. Neoplastic meningitis from systemic malignancies: diagnosis, prognosis and treatment. Semin Oncol. 2006;4:312-23. 
17. Chamberlain MC, Glantz M, Groves MD, Wilson WH. Diagnostic tools for neoplastic meningitis: detecting disease, identifying patient risk, and determining benefit of treatment. Semin Onco. 2009;36 Suppl 2:35-45.

18. Chamberlain MC. Leptomeningeal metastasis. Curr Opin Oncol. 2010;22: 627-35.

19. Chamberlain MC. Neoplastic meningitis. Neurologist. 2006;12:179-87.

20. Chamberlain MC. Neoplastic meningitis. In: Rees J, Wen PY, editors. Neurooncology, blue books of neurology series. 2010. p. 333-51.

21. Mammoser AG, Groves MD. Biology and therapy of neoplastic meningitis. Curr Oncol Rep. 2010;12:41-9.

22. Pestalozzi BC, Zahrieh D, Price KN, Holmberg SB, Lindtner J, Collins J, et al. Identifying breast cancer patients at risk for Central Nervous System (CNS) metastases in trials of the International Breast Cancer Study Group (IBCSG). Ann Oncol. 2006;17:935-44.

23. Tham YL, Sexton K, Kramer R, Hilsenbeck S, Elledge R. Primary breast cancer phenotypes associated with propensity for central nervous system metastases. Cancer. 2006:107:696-704.

24. Slimane K, Andre F, Delaloge S, Dunant A, Perez A, Grenier J, et al. Risk factors for brain relapse in patients with metastatic breast cancer. Ann Oncol. 2004;15:1640-4

25. de Azevedo CR, Cruz MR, Chinen LT, Peres SV, Peterlevitz MA, de Azevedo Pereira $A E$, et al. Meningeal carcinomatosis in breast cancer: prognostic factors and outcome. J Neurooncol. 2011;104:565-72.

26. Miller KD, Weathers T, Haney LG, Timmerman R, Dickler M, Shen J, et al. Occult central nervous system involvement in patients with metastatic breast cancer: prevalence, predictive factors and impact on overall survival. Ann Oncol. 2003;14:1072-7.

27. Le Rhun E, Taillibert S, Zairi F, Devos P, Pierret MF, Dubois F, et al. Clinicopathological features of breast cancer predict the development of leptomeningeal metastases: a case-control study. J Neurooncol. 2011;105:309-15.

28. Elston CW, Ellis IO. Pathological prognostic factors in breast cancer. I. The value of histological grade in breast cancer: experience from a large study with long-term follow-up. Histopathology. 1991;19:403-10.

29. Tabár L, Chen HH, Duffy SW, Yen MF, Chiang CF, Dean PB, et al. A novel method for prediction of long-term outcome of women with T1a, T1b and 10-14 mm invasive breast cancers: a prospective study. Lancet. 2000; 355:429-33.

30. Hammond MEH, Hayes DF, Dowsett M, Allred DC, Hagerty KL, Badve S, et al. American Society of Clinical Oncology/College of American Pathologists guideline Recommendations for immunohistochemical testing of estrogen and progesterone receptors in Breast Cancer. J Clin Oncol. 2010;28:2784-95.

31. Wolff AC, Hammond ME, Schwartz JN, Hagerty KL, Allred DC, Cote RJ, et al. American Society of Clinical Oncology/College of American Pathologists guideline Recommendations for human Epidermal Growth Factor receptor 2 Testing in Breast Cancer. J Clin Oncol. 2007;25:118-45.

32. Castellano I, Chiusa L, Vandone AM, Beatrice S, Goia M, Donadio M, et al. A simple and reproducible prognostic index in luminal ER-positive breast cancers. Ann Oncol. 2013:24:2292-7.

33. Taillibert S, Laigle-Donadey F, Chodkiewicz C, Sanson M, Hoang-Xuan K, Delattre JY. Leptomeningeal metastases from solid malignancy: a review. J Neuro-Oncol. 2005;75:85-99.

34. Wasserstrom WR, Glass JP, Posner JB. Diagnosis and treatment of leptomeningeal metastasis from solid tumors: experience with 90 patients. Cancer. 1982;49:759-72

35. Lara-Medina F, Crismatt A, Villareal-Garza C, Alvarado-Miranda A, FloresHernández L, González-Pinedo M, et al. Clinical features and prognostic factors in patients with carcinomatous meningitis secondary to breast cancer. Breast J. 2012:18:233-41.

36. Meattini I, Livi L, Saieva C, Franceschini D, Marrazzo L, Greto D, et al. Prognostic factors and clinical features in patients with leptominengeal metastases from breast cancer: a single center experience. J Chemother. 2012;24:279-84.

37. Niwinska A, Rudnicka H, Murawska M. Breast cancer leptomeningeal metastasis: propensity of breast cancer subtypes for leptomeninges and the analysis of factors influencing survival. Med Oncol. 2013;30:408-15.

38. Torrejón D, Oliveira M, Cortes J, Sanchez-Olle J, Gómez P, Bellet M, et al. Implication of breast cancer phenotype for patients with leptomeningeal carcinomatosis. Breast. 2013;22:19-23.
39. Le Rhun E, Taillibert S, Zairi F, Kotecki N, Devos P, Mailliez A, et al. A retrospective case series of 103 consecutive patients with leptomeningeal metastasis and breast cancer. J Neurooncol. 2013;113:83-92.

40. Chamberlain MC, Soffietti R, Raizer J, Rudà R, Brandsma D, Boogerd W, et al. Leptomeningeal metastasis: a response assessment in neuro-oncology critical review of endpoints and response criteria of published randomized clinical trials. Neuro-Oncology. 2014;16:1176-85.

\section{Submit your next manuscript to BioMed Central and we will help you at every step:}

- We accept pre-submission inquiries

- Our selector tool helps you to find the most relevant journal

- We provide round the clock customer support

- Convenient online submission

- Thorough peer review

- Inclusion in PubMed and all major indexing services

- Maximum visibility for your research

Submit your manuscript at www.biomedcentral.com/submit
) Biomed Central 